\section{BRAZIULAN JOURNAL \\ OF MEDICAL AND BIOLOGICAL RESEARCH}

www.bjournal.com.br
ISSN 1414-431X

Volume 45 (12) 1102-1340 December 2012

\section{BIOMIDICAL SCIENCES}

AND

CLINICAL INVESTIGATION

Braz J Med Biol Res, December 2012, Volume 45(12) 1141-1149

doi: 10.1590/S0100-879X2012007500145

Gene transfer of Chlorella vulgaris n-3 fatty acid desaturase optimizes the fatty acid composition of human breast cancer cells

Meilan Xue, Yinlin Ge, Jinyu Zhang, Qing Wang and Lin Hou

The Brazilian Journal of Medical and Biological Research is partially financed by

\section{욛NPq}

da Ciência e Tecnologia

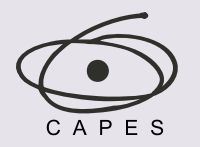

Ministério da Educação

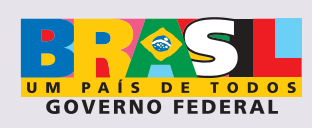

DTFAPESP

Institutional Sponsors

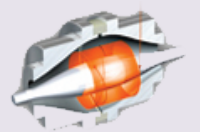

๑ SHIMADZU UNICAMP

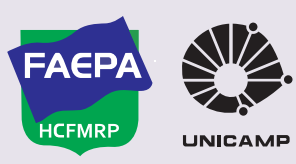

lore High - Performance MS Orbitrap Technology In Proteomics \& Metabolomics

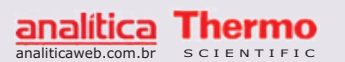




\title{
Gene transfer of Chlorella vulgaris n-3 fatty acid desaturase optimizes the fatty acid composition of human breast cancer cells
}

\author{
Meilan Xue ${ }^{1}$, Yinlin $\mathrm{Ge}^{1}$, Jinyu Zhang ${ }^{1}$, Qing Wang ${ }^{2}$ and Lin Hou ${ }^{1}$ \\ ${ }^{1}$ Department of Biochemistry and Molecular Biology, Medical College, Qingdao University, \\ Qingdao, Shandong, China \\ ${ }^{2}$ Affiliated Hospital of Qingdao University, Qingdao, Shandong, China
}

\begin{abstract}
Chlorella vulgaris has the gene of $n-3$ fatty acid desaturase (CvFad3), which can synthesize the precursor of n-3 polyunsaturated fatty acids (PUFAs) or convert n-6 to n-3 PUFAs. The objective of the present study was to examine whether the CvFad3 gene from $C$. vulgaris can be functionally and efficiently expressed in human breast cancer cells and whether its expression can exert a significant effect on cell fatty acid composition. We inserted the CvFad3 gene into the plasmid pEGFP-C3 to construct the eukaryotic expression vector pEGFP-C3-n-3 and to express the n-3 Fad gene in human breast cancer cells (MCF-7 cells). Transfection of MCF-7 cells with the recombinant vector resulted in a high expression of $n-3$ fatty acid desaturase. Lipid analysis indicated that the ratio of $n-6 / n-3$ PUFAs was decreased from $6: 1$ in the control cells to about 1:1 in the cells expressing the $\mathrm{n}-3$ fatty acid desaturase. Accordingly, the CvFad3 gene significantly decreased the ratio of n-6/n-3 PUFAs of the MCF-7 cell membrane. The expression of the CvFad3 gene can decrease cell proliferation and promote cell apoptosis. This study demonstrates that the CvFad3 gene can dramatically balance the ratio of n-6/n-3 PUFAs and may provide an effective approach to the modification of the fatty acid composition of mammalian cells, also providing a basis for potential applications of its transfer in experimental and clinical settings.
\end{abstract}

Key words: Chlorella vulgaris; CvFad3 gene; Fatty acid desaturase; Recombinant expression vector; Fatty acid composition; Breast cancer cells

\section{Introduction}

The biological effects of polyunsaturated fatty acids (PUFAs) have been widely investigated around the world. In particular, their impacts on human health have attracted increasing public attention in recent years. PUFAs mainly include two groups: n-3 PUFAs and n-6 PUFAs. The n-3 PUFAs have been the subject of increasing investigation and have attracted considerable interest as pharmaceutical and nutraceutical compounds (1,2). n-3 PUFAs are beneficial for humans and animals and have been shown to exert preventive and therapeutic effects on some diseases such as cardiovascular diseases, arthritis, cancer, and neuropathic diseases (3-5). Supplementation of diet with n-3 PUFAs has therapeutic effects on inflammatory and autoimmune diseases such as arthritis $(6,7)$. Studies with nonhuman primates (8) and human newborns indicate that n-3 fatty acids are essential for the normal functional development of the retina and brain, particularly in premature infants $(9,10)$. Clinical cancer research indicates that breast and colon cancer can be modified or their growth can be inhibited by adding n-3 PUFAs to the human diet (11-13). n-3 PUFAs have been shown to exert anticancer activity in vitro and in animal models of experimental cancer $(14,15)$. In general, a balanced $n-6 / n-3$ ratio of the body lipids is essential for normal growth and development and plays an important role in the prevention and treatment of many clinical problems (16).

However, humans and mammals are incapable of synthesizing n-3 PUFAs in their bodies, so that the levels of PUFAs in their bodies are, to a large extent, dependent on dietary intake $(17,18)$. Currently, the Western diet contains a disproportionally high amount of n-6 PUFAs and low amounts of n-3 PUFAs, which lead to much lower

Correspondence: Meilan Xue, Department of Biochemistry and Molecular Biology, Medical College, Qingdao University, Dengzhou Roud \#38, Qingdao, Shandong, 266021, China. E-mail: snowml@126.com

Received January 5, 2012. Accepted August 28, 2012. Available online September 14, 2012. Published December 17, 2012. 
levels of n-3 PUFAs compared to n-6 PUFAs in mammals since the ratio of $n-6$ to n-3 PUFAs can be as high as 18 or even higher and is thought to contribute to cardiovascular disease, inflammation, and cancer (19). Therefore, one of the current focal points in the field of health science research is to increase n-3 PUFA content in the diet and to obtain abundant sources of n-3 PUFAs. The acquisition of proper desaturase genes to produce higher levels of $n-3$ PUFAs is one of the keys to solving this problem.

It is known that the $n-3$ fatty acid desaturase (FAD) plays an important role in the synthesis of $n-3$ PUFAs, since it can efficiently covert n-6 PUFAs to n-3 PUFAs. The n-6 and n-3 PUFAs are synthesized through an alternating series of desaturations and elongations beginning with either linoleic acid (LA, 18:2 n-6) or $\alpha$-linolenic acid (ALA, 18:3n-3), respectively. ALA is an essential fatty acid, which has many sanitary functions in humans. However, its content in the diet is often insufficient. In plants, n-3 FAD catalyze LA into ALA. The major end point of the $n-6$ pathway in mammals is arachidonic acid (AA, 20:4 n-6), and the major end-products of the $n-3$ pathway are eicosapentaenoic acid (EPA, 20:5n-3) and docosahexaenoic acid (DHA, 22:6 n-3). The n-3 and n-6 PUFAs are not interconvertible in mammalian cells (17). Thus, LA, ALA, and their elongation and desaturation products are considered to be essential fatty acids in the human diet. The PUFA composition of cell membranes is, to a great extent, dependent on dietary intake $(18,20)$. Nevertheless, some plants, such as Chlorella vulgaris, are able to synthesize the n-3 fatty acid ALA. It has been reported that a $\mathrm{CvFad} 3$ gene from $C$. vulgaris encodes the n-3 FAD; this enzyme, when expressed in Nicotiana tabacum, can catalyze the conversion of n-6 PUFAs to n-3 PUFAs by introducing an n-3 double bond into their hydrocarbon chains (21).

The objective of this study was to examine whether the CvFad3 gene from C. vulgaris can be functionally expressed in mammalian cells in a highly efficient manner and whether its expression can exert a significant effect on cell fatty acid composition.

\section{Material and Methods}

\section{Construction of the recombinant plasmid pEGFP-C3-n-3}

The plasmid pEGFP-C3 (BD Bioscience Clontech, USA) was digested with Xhol and EcoRI (Promega, USA), and fractionated on $1 \%$ agarose gels, and the longer band was purified. The fragment of the CvFad3 gene was amplified from mRNA of $C$. vulgaris by RT-PCR and then inserted into the plasmid of pEGFP-C3 (shown in Figure 1), as described in detail below. The long segment pEGFP-C3 and the CvFad3 gene were ligated at 1:4 ( $\mathrm{mol} / \mathrm{mol})$ by T4 ligase. The structure of the construct was confirmed by enzymatic digestion and DNAsequencing. The eukaryotic recombinant expression vector was named pEGFP-C3-n-3.

\section{Cell cultures and transfection with recombinant plasmid}

MCF-7 cells were obtained from Shanghai Life Science, Chinese Academy of Sciences. MCF-7 cells were maintained routinely in a 1:1 (v/v) mixture of high glucose DMEM and $10 \%(\mathrm{v} / \mathrm{v})$ fetal bovine serum at $37^{\circ} \mathrm{C}$ in a tissue culture incubator with $5 \% \mathrm{CO}_{2}$ and $98 \%$ relative humidity. MCF-7 cells were added to 6 -well plates and cultured by standard procedure. The cell number and medium volume were the same in each well. After $24 \mathrm{~h}$ of culture, cells were transfected with the recombinant plasmid pEGFP-C3-n-3 and pEGFP-C3-control for experiments to be conducted when $75 \%$ of the plate was covered with cells. Transfections were carried out by adding the Xfect polymer to the same culture medium with serum. After 5 -h incubation, the transfection medium was replaced with normal culture medium. After 48-h incubation, cells were photographed and analyzed for gene expression and fatty acid composition.

\section{Cell growth and viability assay (MTT)}

Cell growth and viability were determined with the cell proliferation kit I (MTT, Roche Diagnostics Corporation, Germany). MCF-7 cells ( $1 \times 10^{4}$ plaque-forming units $/ \mathrm{mL}$ ) were grown on 96 -well culture plates. Two groups were set up for pEGFP-C3-n-3 and pEGFP-C3-control. Each group had 10 parallel wells. After $48 \mathrm{~h}$ of transfection, $20 \mu \mathrm{L}$ MTT

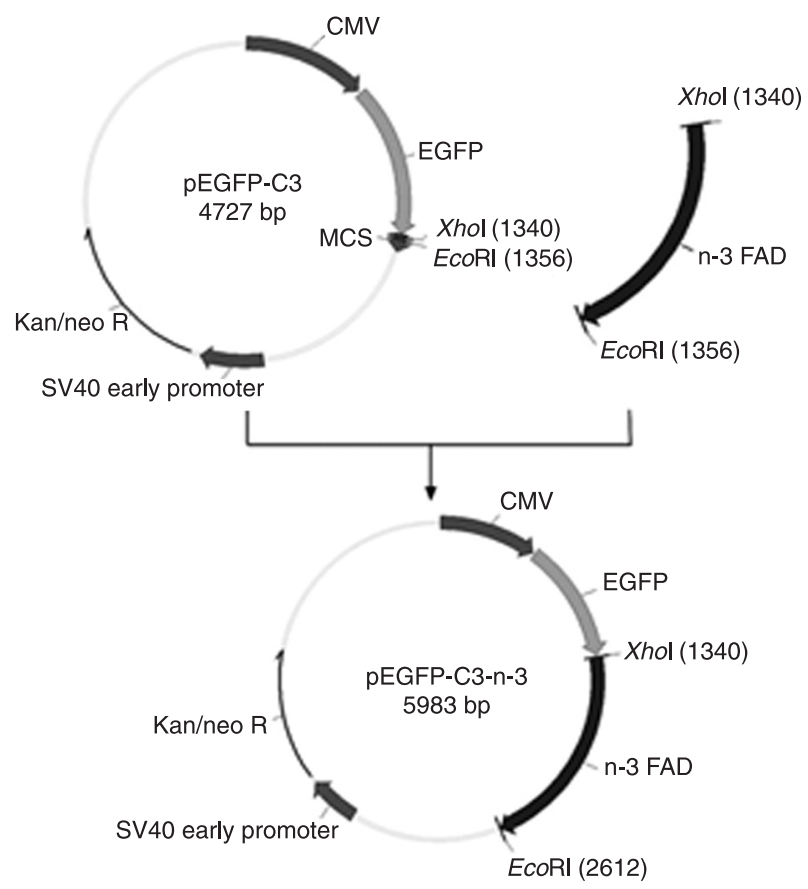

Figure 1. Construction of the recombinant plasmid pEGFP-C3n-3. EGFP = enhanced green fluorescent protein; CMV = cytomegalovirus; FAD = fatty acid desaturase. 
( $5 \mathrm{mg} / \mathrm{mL}$ ) labeling reagent was added to each well (100 $\mu \mathrm{L}$ medium). The plates were incubated with $50 \mathrm{~mL} / \mathrm{L} \mathrm{CO}_{2}$ at $37^{\circ} \mathrm{C}$ for $4 \mathrm{~h}$, the medium was discarded, and $100 \mu \mathrm{L}$ of the solubilization solution was then added to each well. Complete solubilization of the purple formazan crystals was confirmed and the absorbance of the solution at 490 $\mathrm{nm}$ was determined.

\section{RNA analysis}

Briefly, total RNA was extracted from cultured cells, which were transfected after $48 \mathrm{~h}$ by using a total RNA isolation regent (Trizol, Invitrogen, USA) according to the manufacturer protocol. The CvFad3 gene fragment was amplified and the reverse transcription-polymerase chain reaction (RT-PCR) was performed. The forward and reverse primers were 5'-TTGCCGCTCCTGCCGAAGA-3' and 5'-GGGTCACTGGGTCCGTGATGGT-3', respectively. The conditions for amplification were $94^{\circ} \mathrm{C}$ for $3 \mathrm{~min}, 94^{\circ} \mathrm{C}$ for $30 \mathrm{~s}, 61^{\circ} \mathrm{C}$ for $40 \mathrm{~s}, 72^{\circ} \mathrm{C}$ for $1 \mathrm{~min}$, and $72^{\circ} \mathrm{C}$ for $10 \mathrm{~min}$. The amplification products were $793 \mathrm{bp}$ and the band was subjected to autoradiography.

\section{Lipid analysis}

After $48 \mathrm{~h}$ of transfection, the MCF-7 cells were collected from 6 -well plates. The fatty acid composition of total cell lipids was analyzed as described (22). Lipid was extracted with chloroform/methanol $(2: 1, \mathrm{v} / \mathrm{v})$ containing $0.005 \%$ butylated hydroxytoluene as antioxidant. Fatty acid methyl esters were prepared using a $14 \%(w / v)$ BF3/methanol reagent. Fatty acid methyl esters were quantified by GC/MS using an HP-5890 Series II gas chromatograph equipped with a Supelcowax SP-10 capillary column (Supelco, USA) attached to an HP-5971 mass spectrometer. The injector and detector were maintained at $260^{\circ}$ and $280^{\circ} \mathrm{C}$, respectively. The oven program was maintained initially at $150^{\circ} \mathrm{C}$ for $2 \mathrm{~min}$, then increased to $200^{\circ} \mathrm{C}$ at $10^{\circ} \mathrm{C} / \mathrm{min}$ and held for $4 \mathrm{~min}$, increased again at $5^{\circ} \mathrm{C} / \mathrm{min}$ to $240^{\circ} \mathrm{C}$ and held for $3 \mathrm{~min}$, and finally increased to $270^{\circ} \mathrm{C}$ at $10^{\circ} \mathrm{C} / \mathrm{min}$ and maintained for $5 \mathrm{~min}$. The carrier gas-flow rate was maintained at $0.8 \mathrm{~mL} / \mathrm{min}$. Total ion monitoring was performed, encompassing mass ranges from 50 to 550 atomic mass units. Fatty acid mass was determined by comparing the areas of the various fatty acids analyzed to the areas of a fixed concentration of the internal standard.

\section{Measurement of eicosanoids}

Prostaglandin $\mathrm{E}_{2}\left(\mathrm{PGE}_{2}\right)$ was measured with the mouse $\mathrm{PGE}_{2}$ ELISA kit (R\&D, USA) following the manufacturer protocol. After 48-h transfection, the medium of the 3T3 cells was collected and subjected to eicosanoid measurement.

\section{Cell cycle and apoptosis analysis}

After 48-h transfection, MCF-7 cells were collected from 6-well plates. Cell cycle and apoptosis were then determined using the Vybrant Apoptosis Assay Kit (Invitrogen), according to the manufacturer protocol, and measured by fluorescence-activated cell sorting using a FACScan flow cytometer (Becton Dickinson, USA).

\section{Data analysis}

Cell growth and viability data (MTT), $\mathrm{PGE}_{2}$ and fatty acid composition were analyzed with the GraphPad Prism 5 software. The data of cell cycle and apoptosis were analyzed with the WinMDI 2.9 software and each experiment was repeated 3 times. Data are reported as means $\pm S D$. The data of PUFA composition were analyzed by one-way ANOVA followed by the Bonferroni $t$-test. The other data were analyzed by the Student $t$-test. The level of significance was set at $\mathrm{P}<0.05$.

\section{Results}

\section{Enzymatic digestion of recombinant plasmid pEGFP-C3-n-3}

Recombinant plasmid pEGFP-C3-n-3 was digested with the fast digest $X h o l$ and $E c o R I$, and the result corresponded to plasmid pEGFP-C3 and the objective CvFad3 gene (shown in Figure 2).

\section{Expression of the CvFad3 gene in MCF-7 cells}

The coexpression of EGFP allowed us to identify the cells

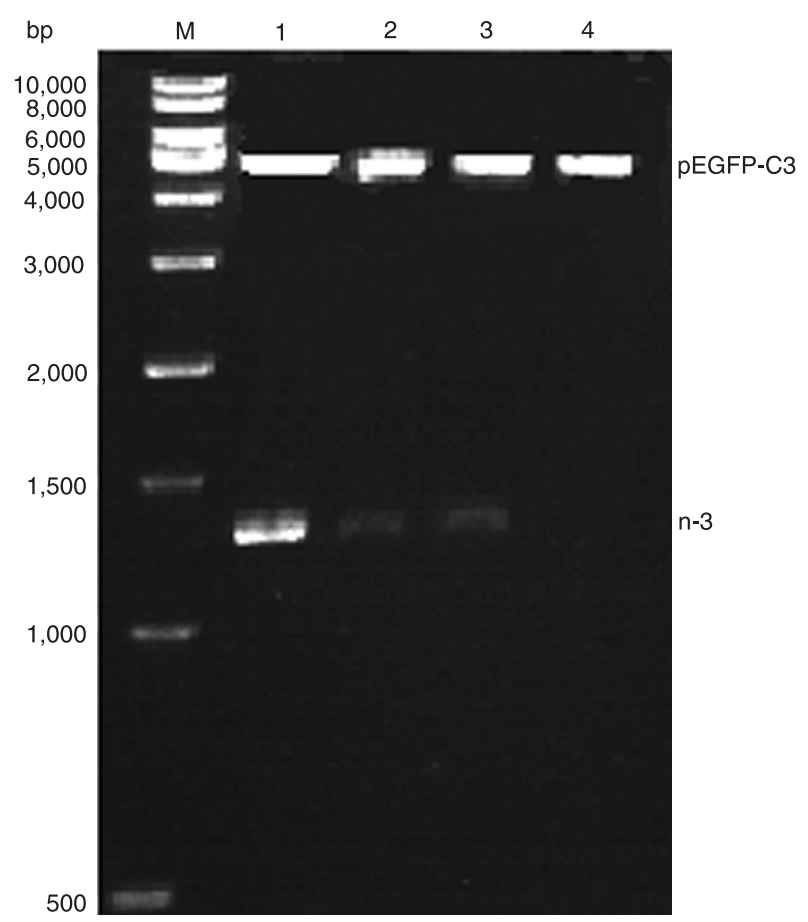

Figure 2. Identification of the recombinant plasmids pEGFP-C3$\mathrm{n}-3$ and pEGFP-C3 by double enzyme Xhol/EcoRl digestion. Lane $M=1-\mathrm{kb}$ DNA ladder; lanes 1, 2, $3=X$ hol $/ E c o R l$ digest pEGFP-C3-n-3; lane $4=\mathrm{Xhol} / E \mathrm{EcoRI}$ digest pEGFP-C3. PCR products were observed on $1.0 \%$ agarose gel electrophoresis. 
that were transfected and that expressed the transgene. The result is shown in Figure 3; $48 \mathrm{~h}$ after transfection about $40 \%$ of the cells exhibited bright fluorescence, indicating a high efficiency of gene transfer and a high expression level of the transgene.

Furthermore, the expression profile of the transgene was also determined by RT-PCR. As shown in Figure 4, the mRNA of the CvFad3 gene was not detected in cells transfected with pEGFP-C3-control but was abundant in cells transfected with $p E G F P-C 3-n-3$. The results indicate that the CvFad3 gene has a very high expression in MCF-7 cells transfected with pEGFP-C3-n-3.

\section{n-3 desaturase activity and its effect on fatty acid composition}

We tested whether the expression of the CvFad3 gene in MCF-7 cells can lead to conversions of $n-6$ fatty acids to n-3 fatty acids and, thereby, to a change in fatty acid composition. The fatty acid composition of total cellular lipids was analyzed by gas chromatography and the results were summarized in Figure 5 and Table 1 . The fatty acid profiles differ remarkably between the control cells transfected only with pEGFP-C3 and the cells transfected with pEGFP-C3$n-3$. In the cells expressing the CvFad3 gene, n- 6 fatty acids were converted largely to the corresponding $n-3$ fatty acids, namely, $18: 2$ n-6 to $18: 3 n-3$, and $20: 4 n-6$ to $20: 5 n-3$. As
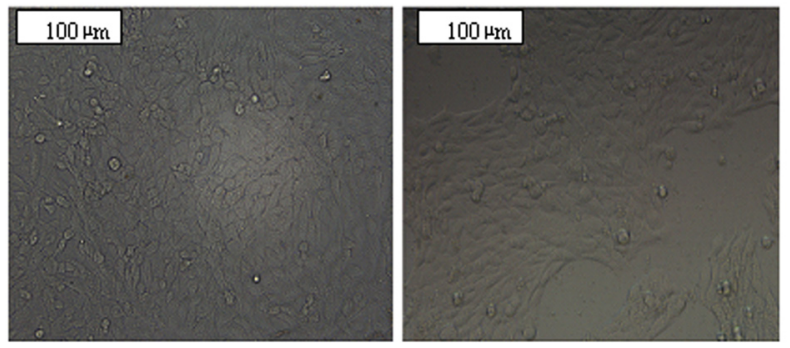

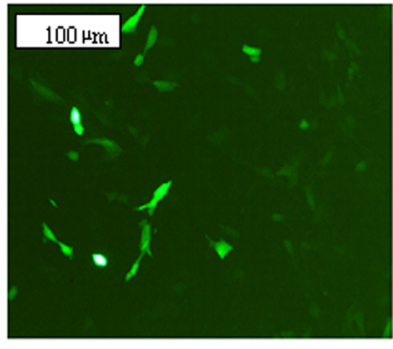

pEGFP-C3-control

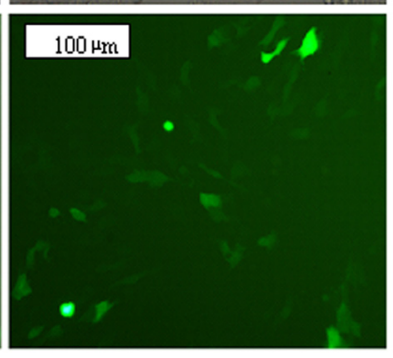

pEGF-C3-n-3
Figure 3. Photomicrographs showing gene transfer efficiency (200X magnification). MCF-7 cells were transfected with pEGFPC3-control or pEGFP-C3-n-3. Forty-eight hours after tranfection, many cells in the two groups exhibited bright fluorescence showing that plasmid pEGFP-C3-n-3 and pEGFP-C3 were successfully transfected into MCF-7 cells. About $40 \%$ of the cells exhibited bright fluorescence in the pEGFP-C3-n-3 group, indicating a high efficiency of gene transfer and a high expression level of the transgene. a result, the fatty acid composition of the cells expressing the n-3 FAD was changed significantly when compared to that of the control cells transfected with pEGFP-C3-control or that of non-transfected cells (Table 1). Importantly, the $\mathrm{n}-6 / \mathrm{n}-3$ ratio was reduced from $6: 1$ in the control cells to about $1: 1$ in the cells expressing the $n-3$ FAD.

\section{Effect on eicosanoid production}

Because 20:4 n-6 (AA) and 20:5 n-3 (EPA) are the precursors of 2- and 3-series of eicosanoids, respectively, differences in the contents of AA and EPA may lead to a difference in the production of eicosanoids in the cells. Thus, we measured the production of eicosanoids in the

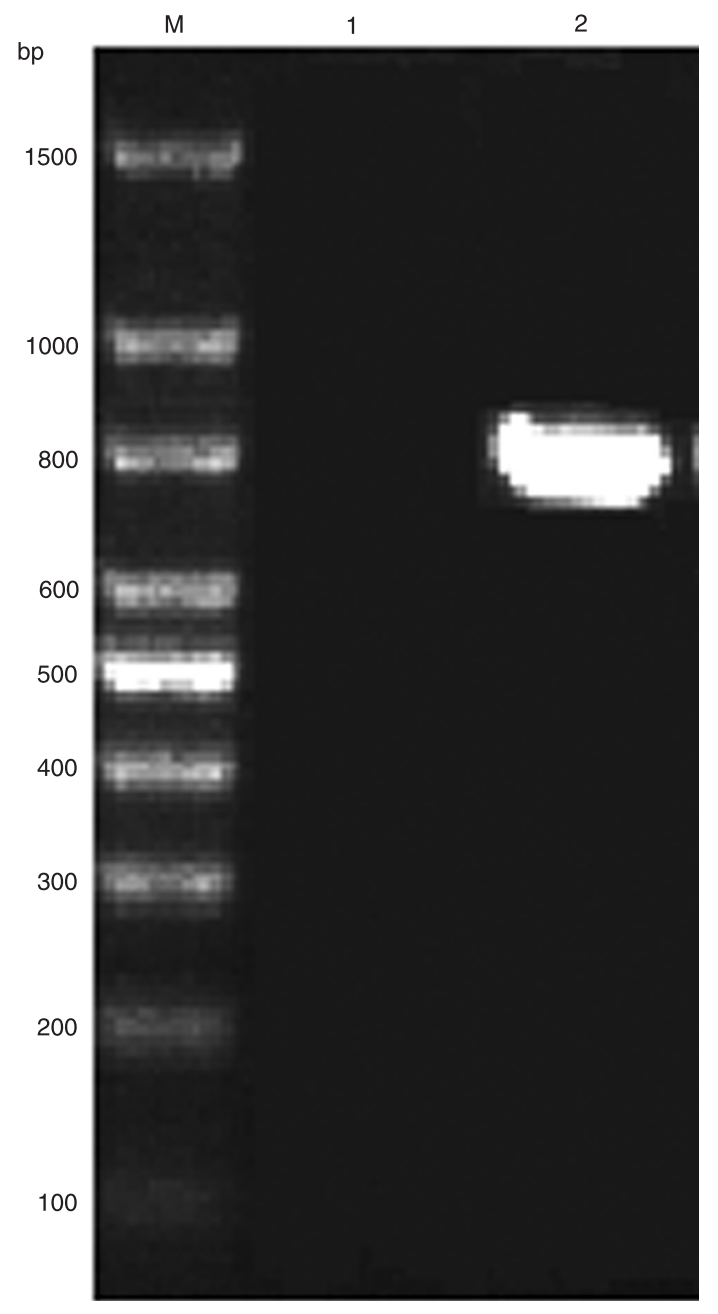

Figure 4. Result of $n-3$ fatty acid desaturase (FAD) transcript levels in MCF-7 cells transfected with pEGFP-C3-control and pEGFP-C3-n-3 after $48 \mathrm{~h}$. Lane $M=100$-bp DNA ladder; lane 1 = pEGFP-C3-control group; lane 2 = pEGFP-C3-n-3 group. PCR products were observed on $2.0 \%$ agarose gel electrophoresis. This result indicates that CvFad3 mRNA was not detected in MCF-7 cells transfected with pEGFP-C3-control, but was highly abundant in MCF-7 cells transfected with pEGFP-C3-n-3. 


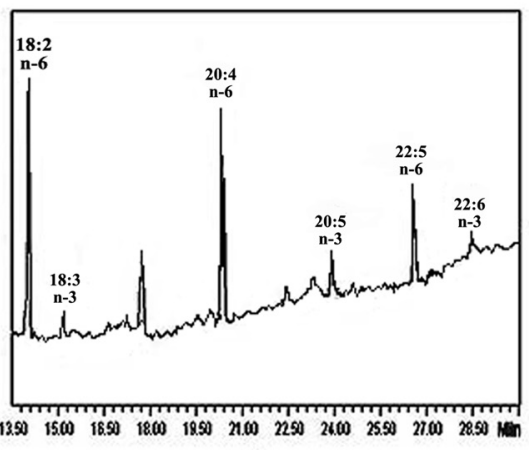

A

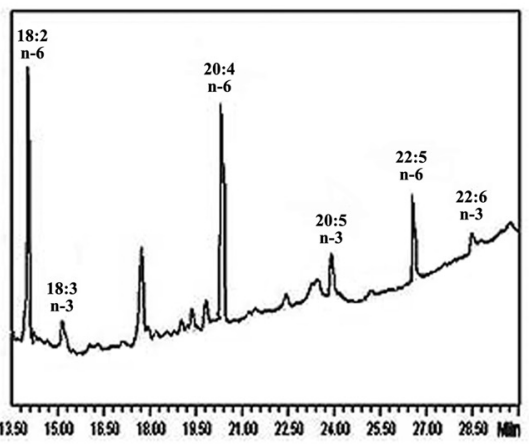

$\mathrm{B}$

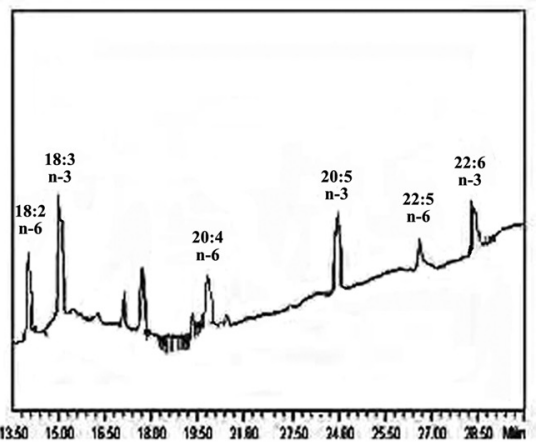

$\mathrm{C}$

Figure 5. Partial gas chromatography traces showing fatty acid profiles of total cellular lipids extracted from non-transfected cells, control cells transfected with pEGFP-C3-control and cells transfected with pEGFP-C3-n-3. A, Non-transfected group. B, pEGFP-C3control group. C, pEGFP-C3-n-3 group. The fatty acid profiles in the cells transfected with the pEGFP-C3-n-3 are remarkably different from those of non-transfected cells or of the control cells transfected with the pEGFP-C3. In the cells expressing the CvFad3 gene, n- 6 fatty acids were converted largely to the corresponding n-3 fatty acids, namely, 18:2 n-6 to 18:3 n-3, and 20:4 n-6 to 20:5 n-3.

Table 1. PUFA composition of total cellular lipids from the control MCF-7 cells and the transgenic cells, which express the CvFad3 gene.

\begin{tabular}{cccc}
\hline $\begin{array}{l}\text { PUFA } \\
\text { composition }\end{array}$ & $\begin{array}{c}\text { Non-transfected } \\
\text { group }\end{array}$ & $\begin{array}{c}\text { Control } \\
\text { group }\end{array}$ & $\begin{array}{c}\text { Experimental } \\
\text { group }\end{array}$ \\
\hline n-6 PUFAs & & & \\
$18: 2 \mathrm{n}-6$ & $5.95 \pm 0.131$ & $6.02 \pm 0.156$ & $2.24 \pm 0.051^{\text {*\# }}$ \\
$20: 4 \mathrm{n}-6$ & $4.67 \pm 0.064$ & $4.74 \pm 0.059$ & $1.72 \pm 0.049^{\text {*\# }}$ \\
$22: 5 \mathrm{n}-6$ & $1.94 \pm 0.037$ & $1.80 \pm 0.042$ & $0.87 \pm 0.041^{\text {*\# }}$ \\
Total & 12.54 & 12.56 & 4.83 \\
$\mathrm{n}-3$ PUFAs & & & \\
18:3 n-3 & $0.89 \pm 0.057$ & $86 \pm 0.045$ & $2.95 \pm 0.078^{\star \#}$ \\
$20: 5 \mathrm{n}-3$ & $0.78 \pm 0.052$ & $74 \pm 0.044$ & $2.14 \pm 0.056^{\text {*\# }}$ \\
$20: 6 \mathrm{n}-3$ & $0.52 \pm 0.041$ & $47 \pm 0.032$ & $1.05 \pm 0.035^{\star \#}$ \\
Total & 2.19 & 2.07 & 6.14 \\
$\mathrm{n}-6 / \mathrm{n}-3$ ratio & 5.72 & 6.07 & 0.79 \\
\hline
\end{tabular}

Data are reported as area percentage (means $\pm S D, N=3$ ). The fatty acid profiles in the cells transfected with pEGFP-C3-n-3 are remarkably different from those of non-transfected cells or those of the control cells transfected with the pEGFP-C3. In the cells expressing the CvFad3 gene, $n-6$ fatty acids were converted largely to the corresponding n-3 fatty acids, namely, $18: 2 n-6$ to $18: 3 n-3$, and $20: 4 n-6$ to $20: 5 n-3$. As a result, the fatty acid composition of the cells expressing the $n-3$ fatty acid desaturase was changed significantly when compared to that of the control cells transfected with pEGFP-C3-control. Importantly, the ratio of $n-6 / n-3$ was reduced from $6: 1$ in the control cells to about $1: 1$ in the cells expressing the $\mathrm{n}-3$ fatty acid desaturase. ${ }^{*} \mathrm{P}<0.05$ compared to control group; ${ }^{\mathrm{P}}<0.05$ compared to the non-transfected group (one-way ANOVA followed by the Bonferroni $t$-test).

transfected cells using an enzyme immunoassay kit. As shown in Figure 6, the amount of $\mathrm{PGE}_{2}$ produced by the cells transfected with $\mathrm{pEGFP-C3-n-3}$ was significantly lower than that of the control cells $(P<0.05)$.

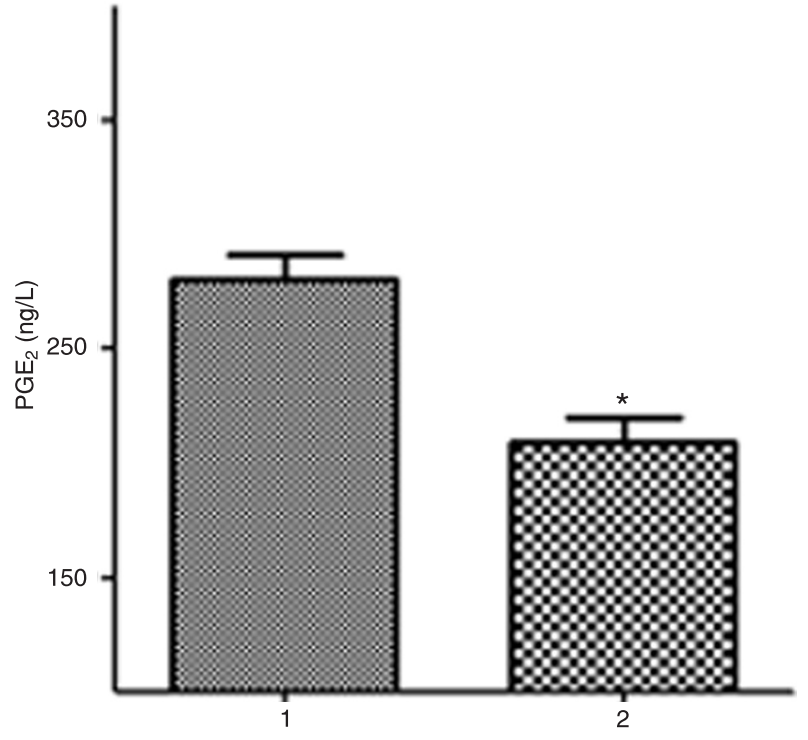

Figure 6. Enzyme immunoassay of prostaglandin $\mathrm{E}_{2}\left(\mathrm{PGE}_{2}\right)$ levels in the control cells and in the cells expressing $n-3$ fatty acid desaturase. 1 = pEGFP-C3-control group; 2 = pEGFP-C3-n-3 group. The level of $\mathrm{PGE}_{2}$ in cells transfected with pEGFP-C3-n-3 was lower than that of the control cells. ${ }^{*} \mathrm{P}<0.05$ compared to control (Student $t$-test).

\section{Change of cell proliferation}

To investigate the effect of the expression of the CvFad3 gene on MCF-7 cell growth, we analyzed cell proliferation. As shown in Figure 7, in the result of the MTT kit (cell growth and viability assay), the absorbance of control cells was higher than that of the experimental group. That is to say, the growth and viability of control cells were higher than those of experimental cells with the CvFad3 gene, because the greater the number of live cells or the lower the number 
of dead cells, the higher the absorbance of cells at $490 \mathrm{~nm}$ $(P<0.01)$. This indicates that the expression of the CvFad3 gene can cause MCF-7 cells to die and/or can inhibit their growth, leading to a decrease of cell proliferation.

\section{Change of cell cycle and apoptosis}

Compared to cells transfected with pEGFP-C3-control, in the MCF-7 cells transfected with pEGFP-C3-n-3, the percent of the $G_{0} / G_{1}$ period was lower $(P<0.01)$ while the percent of the $G_{2} / M$ period was higher $(P<0.01)$; the percent of the $S$ period and APO period obviously increased (both $P<0.01$, Figure 8, Table 2). These results indicate that the CvFad3 gene could inhibit MCF-7 cell proliferation, that the cell cycle is blocked in the $\mathrm{G}_{2} / \mathrm{M}$ period, and that cells could not divide subsequently. Apoptosis analysis showed that the percent of early apoptosis and late apoptosis was higher in the MCF-7 cells transfected with pEGFP-C3-n-3-control compared to cells transfected with pEGFP-C3-control $(\mathrm{P}<$ 0.01, Figure 9, Table 3).

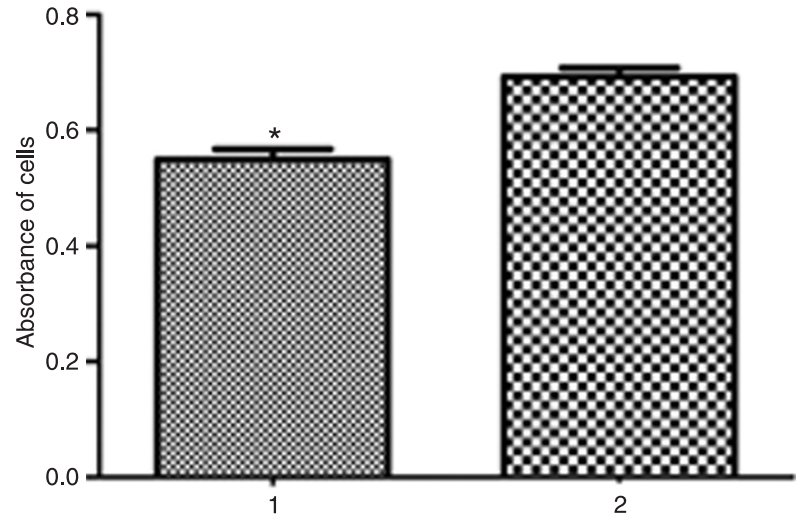

Figure 7. Proliferation of MCF-7 cells (the control cells and the cells expressing $n-3$ fatty acid desaturase) was assessed by MTT. 1 = pEGFP-C3-n-3 group; 2 = pEGFP-C3-control group. The absorbance of cells transfected with pEGFP-C3-n-3 was lower than that of the cells transfected with pEGFP-C3-control. ${ }^{*} \mathrm{P}<0.05$ compared to control (Student $t$-test).
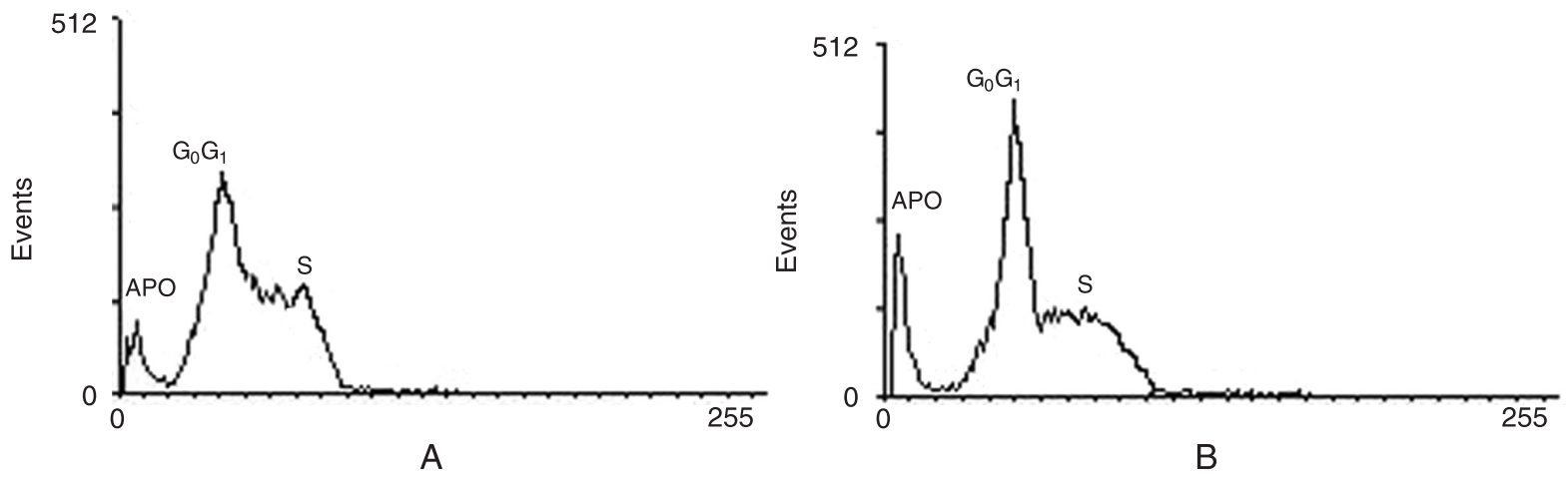

Figure 8. Effect of transfection on the cell cycle. A, pEGFP-C3-control group. B, pEGFP-C3-n-3 group. In the MCF-7 cells transfected with pEGFP-C3-n-3, the percent of the $G_{0} / G_{1}$ and APO periods was increased ( $P<0.05$ for both), while the percent of the $G_{2} / M$ and $S$ periods was decreased ( $P<0.05$ for both, Student $t$-test).

Table 2. Change of the control MCF-7 cells and the transgenic cells expressing the CvFad3 gene in cell cycle and apoptosis.

\begin{tabular}{lllll}
\hline Group & $\mathrm{G}_{0} / \mathrm{G}_{1}$ period & \multicolumn{1}{c}{$\mathrm{G}_{2} / \mathrm{M}$ period } & \multicolumn{1}{c}{ S period } & APO period \\
\hline Control & $43.64 \pm 0.3118$ & $20.83 \pm 0.2805$ & $33.76 \pm 0.1044$ & $1.767 \pm 0.1528$ \\
Experimental & $53.49 \pm 0.3955^{*}$ & $15.47 \pm 0.3676^{*}$ & $25.87 \pm 0.5105^{*}$ & $3.200 \pm 0.1000^{*}$ \\
\hline
\end{tabular}

Data are reported as means \pm SD of three independent experiments. Compared with cells transfected with pEGFP-C3-control, in the MCF-7 cells transfected with pEGFP-C3-n-3, the percent of the $\mathrm{G}_{0} / \mathrm{G}_{1}$ period was lower, while the percent of the $\mathrm{G}_{2} / \mathrm{M}$ period was higher; the percent of the S period and APO period obviously increased. These results indicate that the CvFad3 gene could inhibit MCF-7 cell proliferation, that the cell cycle is blocked in the $\mathrm{G}_{2} / \mathrm{M}$ period, and that cells could not cleave subsequently. ${ }^{*} \mathrm{P}$ $<0.05$ compared to control (Student $t$-test). 
A

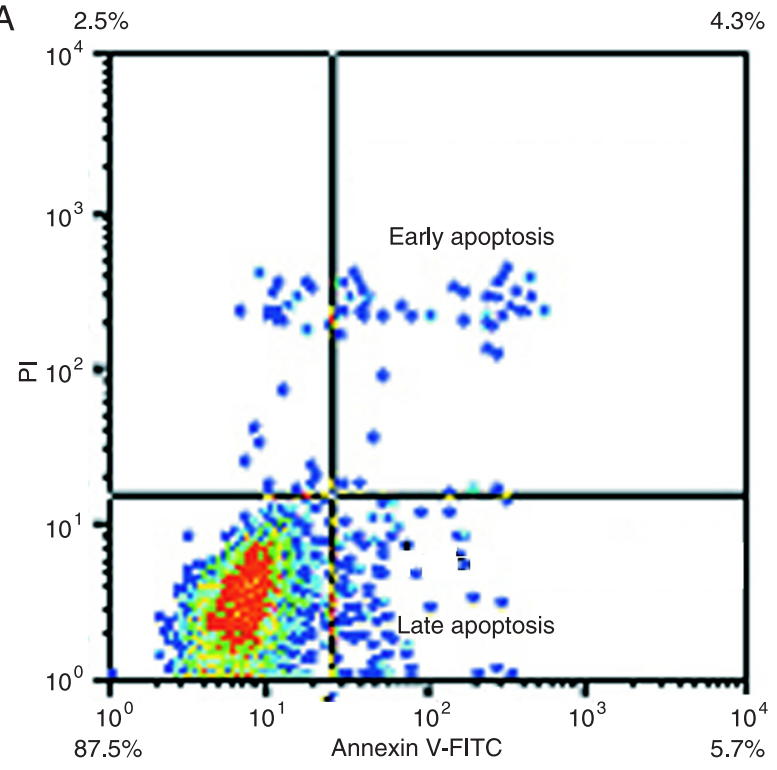

B

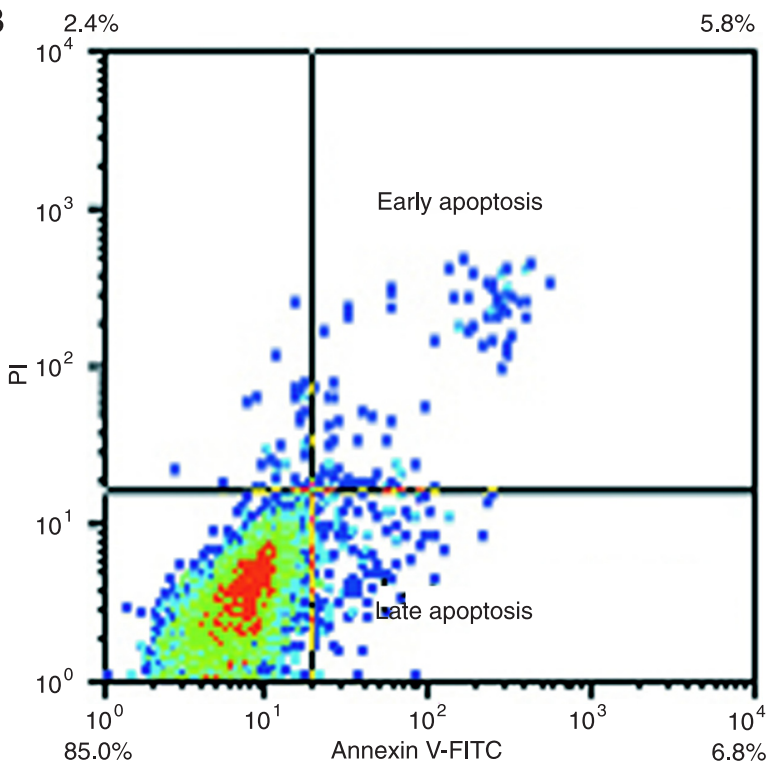

Figure 9. Effect of transfection on the cell apoptosis. A, pEGFP. C3-control group. $B$, pEGFP-C3-n-3 group. $\mathrm{PI}=$ propidium iodide; FITC = fluorescein isothiocyanate. In the MCF-7 cells transfected with pEGFP-C3-n-3, the percent of early apoptosis and late apoptosis was higher $(P<0.01$, Student $t$-test).

\section{Discussion}

In this study, we expressed the construct in MCF-7 cells to estimate the product activity as well as the expression of the CvFad3 gene in mammals. This study has clearly demonstrated that the CvFad3 gene from $C$. vulgaris can be expressed functionally in human breast cancer cells, and its expression could confer on the cells the ability to convert $\mathrm{n}-6$ PUFAs to the corresponding n-3 PUFAs, leading to a
Table 3. The early apoptosis and late apoptosis of the control MCF-7 cells and the transgenic cells expressing the CvFad3 gene.

\begin{tabular}{lcc}
\hline Group & Early apoptosis & Late apoptosis \\
\hline Control & $4.13 \pm 0.167$ & $5.60 \pm 0.208$ \\
Experimental & $5.90 \pm 0.100^{*}$ & $6.63 \pm 0.088^{\star}$ \\
\hline
\end{tabular}

Data are reported as means \pm SD from three repeated experiments. Apoptosis analysis showed that the percent of early apoptosis and late apoptosis was higher in the MCF-7 cells transfected with pEGFP-C3-n-3 compared to cells transfected with pEGFPC3-control. ${ }^{*} \mathrm{P}<0.05$ compared to control group (Student $t$-test).

balanced $n-6 / n-3$ ratio, that could inhibit cell growth and induce apoptosis in breast cancer cells.

We know that n-6 PUFAs stimulate animal tumors and cancer growth and metastasis, whereas n-3 PUFAs exhibit inhibitory effects. A number of studies have shown n-3 fatty acid protection in rodent models of breast cancer. These include dietary supplementation of mouse transplantable tumors and human cell xenograft models as well as chemically induced tumors in rats (23-26). Many signaling pathways that are relevant to carcinogenesis and tumor progression are differentially affected by $n-3$ and n-6 PUFAs. For instance, n-6 PUFA products were reported to up-regulate and activate cellular signaling mediators including protein kinase $C$, ras, ERK $1 / 2$ and NF-kb, whereas n-3 PUFA products had the opposite effect. The ability of long-chain n-3 PUFAs to induce apoptosis in tumor cells has also been attributed to the increased susceptibility of these cells to lipid peroxidation (27-31). Inhibition of tumor cell growth and invasion by $n-3$ PUFAs in a xenograft animal model was associated with decreased cyclooxygenase-2 and $\mathrm{PGE}_{2}$ levels (32). Thus, n-3 PUFAs may act as natural COX "inhibitors".

Balancing the ratio of $n-6 / n-3$ PUFAs is a significant method for controlling tumor development (33). However, the $n-3$ and n-6 PUFAs are not inter-convertible in the human body because mammalian cells lack the n-3 FAD. With the hectic schedule, poor dietary habits and low quality of food sources that people have today, experts recommend the consumption of nutritional dietary supplements, including fish oil supplements, which help fulfill the nutritional demand of all body organs (decreasing the intake of $n-6$ fatty acids and increasing the intake of n-3 fatty acids) (34). Fish oil is derived from the tissues of deep-sea oily fish, but this oily fish does not actually produce DHA/EPA fatty acids, but instead accumulates them by consuming deep-sea microalgae that produce these fatty acids. C. vulgaris is one kind of deep-sea micro-alga, which contains the CvFad3 gene, encoding n-3 FAD, which can catalyze the conversion of $n-6$ PUFAs to $n-3$ PUFAs. Therefore, an alternative approach that can quickly and effectively increase cellular $n-3$ PUFA content and balance the $n-6 / n-3$ ratio, without the 
need for a lengthy intake of fish oil supplements, would be desirable. Because the lack of an n-3 desaturase gene is the bottleneck for endogenous production of $n-3$ PUFAs in mammals, transfer of the $\mathrm{n}-3$ desaturase gene from deepsea micro-algae to livestock is the key to overcoming this constraint since these animals already possess most of these other desaturases and PUFA elongases (35). This assumption has been shown to be feasible in transgenic mice and pigs generated with the $n-3$ desaturase gene from the roundworm Caenorhabditis elegans. A transgenic mouse model expressing the fat-1 gene increased the ratio of $n-3$ and $n-6$ fatty acids in various tissues. In the tissues and organs of these animals, many kinds of $n-3$ PUFAs were produced by desaturating the corresponding n-6 PUFAs $(36,37)$.

In the present study, we used a eukaryotic recombinant expression vector to transfer the CvFad3 gene from C. vulgaris into human breast cancer cells, to convert n-6 PUFA into n-3 PUFA to increase the level of n-3 PUFA and the n3/n-6 PUFA ratio, and the level of $\mathrm{PGE}_{2}$ was also decreased.

\section{References}

1. Simopoulos AP. Essential fatty acids in health and chronic disease. Am J Clin Nutr 1999; 70: 560S-569S.

2. Salem N Jr, Reyzer M, Karanian J. Losses of arachidonic acid in rat liver after alcohol inhalation. Lipids 1996; 31 (Suppl): S153-S156.

3. Kris-Etherton PM, Hecker KD, Binkoski AE. Polyunsaturated fatty acids and cardiovascular health. Nutr Rev 2004; 62: 414-426.

4. Mozaffarian D, Ascherio A, Hu FB, Stampfer MJ, Willett WC, Siscovick DS, et al. Interplay between different polyunsaturated fatty acids and risk of coronary heart disease in men. Circulation 2005; 111: 157-164.

5. Gaibazzi N, Ziacchi V. Reversibility of stress-echo induced ST-segment depression by long-term oral n-3 PUFA supplementation in subjects with chest pain syndrome, normal wall motion at stress-echo and normal coronary angiogram. BMC Cardiovasc Disord 2004; 4: 1.

6. Ariza-Ariza R, Mestanza-Peralta M, Cardiel MH. Omega-3 fatty acids in rheumatoid arthritis: an overview. Semin Arthritis Rheum 1998; 27: 366-370.

7. James MJ, Gibson RA, Cleland LG. Dietary polyunsaturated fatty acids and inflammatory mediator production. Am J Clin Nutr 2000; 71: 343S-348S.

8. Neuringer M, Connor WE, Lin DS, Barstad L, Luck S. Biochemical and functional effects of prenatal and postnatal omega 3 fatty acid deficiency on retina and brain in rhesus monkeys. Proc Natl Acad Sci U S A 1986; 83: 4021-4025.

9. Uauy R, Mena P, Rojas C. Essential fatty acids in early life: structural and functional role. Proc Nutr Soc 2000; 59: 3-15.

10. Uauy R, Peirano P, Hoffman D, Mena P, Birch D, Birch E. Role of essential fatty acids in the function of the developing nervous system. Lipids 1996; 31 (Suppl): S167-S176.

11. Bougnoux P. n-3 polyunsaturated fatty acids and cancer.
Our experimental results showed that the transgenic construct expressed the protein of interest and the transgene product had biological activity in the transfected mammal cells. Then, we demonstrated that the CvFad3 gene from C. vulgaris was functionally expressed and that its product had a significant effect on the fatty acid composition. The proportion of $n-6$ PUFAs decreased and the proportion of n-3 PUFAs increased considerably, particularly for ALA, DHA and EPA, which correspondingly inhibited cell growth and induced apoptosis in breast cancer cells. All of these results showed that the CvFad3 gene from $C$. vulgaris possesses great value for the production of n-3 PUFAs and cancer cell suppression in transgenic MCF-7 cells.

The findings reported here suggest that gene transfer of the CvFad3 gene from C. vulgaris could be a desirable intervention that could quickly and effectively exert therapeutic and cancer-preventive effects of $n-3$ fatty acids. The molecular mechanisms, which account for these biological effects, are not completely understood. Certainly, further study in this regard is warranted.
Curr Opin Clin Nutr Metab Care 1999; 2: 121-126.

12. Rao CV, Hirose $Y$, Indranie C, Reddy BS. Modulation of experimental colon tumorigenesis by types and amounts of dietary fatty acids. Cancer Res 2001; 61: 1927-1933.

13. Yam D, Peled A, Shinitzky M. Suppression of tumor growth and metastasis by dietary fish oil combined with vitamins $E$ and C and cisplatin. Cancer Chemother Pharmacol 2001; 47: 34-40.

14. Cave WT Jr. Omega-3 polyunsaturated fatty acids in rodent models of breast cancer. Breast Cancer Res Treat 1997; 46: 239-246.

15. Rose DP, Connolly JM. Omega-3 fatty acids as cancer chemopreventive agents. Pharmacol Ther 1999; 83: 217244.

16. Simopoulos AP. Human requirement for $\mathrm{N}-3$ polyunsaturated fatty acids. Poult Sci 2000; 79: 961-970.

17. Clandinin MT, Field CJ, Hargreaves K, Morson L, Zsigmond E. Role of diet fat in subcellular structure and function. Can J Physiol Pharmacol 1985; 63: 546-556.

18. McLennan PL, Abeywardena MY, Charnock JS. Dietary fish oil prevents ventricular fibrillation following coronary artery occlusion and reperfusion. Am Heart $J$ 1988; 116: 709717.

19. Goodnight SH Jr, Harris WS, Connor WE. The effects of dietary omega 3 fatty acids on platelet composition and function in man: a prospective, controlled study. Blood 1981; 58: 880-885.

20. Suga K, Honjoh K, Furuya N, Shimizu H, Nishi K, Shinohara $F$, et al. Two low-temperature-inducible Chlorella genes for delta12 and omega-3 fatty acid desaturase (FAD): isolation of delta12 and omega-3 fad cDNA clones, expression of delta12 fad in Saccharomyces cerevisiae, and expression of omega-3 fad in Nicotiana tabacum. Biosci Biotechnol Biochem 2002; 66: 1314-1327. 
21. Kang JX, Man SF, Brown NE, Labrecque PA, Garg ML, Clandinin MT. Essential fatty acid metabolism in cultured human airway epithelial cells. Biochim Biophys Acta 1992; 1128: 267-274.

22. Weylandt KH, Kang JX, Leaf A. Polyunsaturated fatty acids exert antiarrhythmic actions as free acids rather than in phospholipids. Lipids 1996; 31: 977-982.

23. Gabor H, Hillyard LA, Abraham S. Effect of dietary fat on growth kinetics of transplantable mammary adenocarcinoma in BALB/c mice. J Natl Cancer Inst 1985; 74: 1299-1305.

24. Rose DP, Connolly JM, Rayburn J, Coleman M. Influence of diets containing eicosapentaenoic or docosahexaenoic acid on growth and metastasis of breast cancer cells in nude mice. J Natl Cancer Inst 1995; 87: 587-592.

25. Braden LM, Carroll KK. Dietary polyunsaturated fat in relation to mammary carcinogenesis in rats. Lipids 1986; 21 : 285-288.

26. Takahashi M, Minamoto T, Yamashita N, Kato T, Yazawa K, Esumi $\mathrm{H}$. Effect of docosahexaenoic acid on azoxymethaneinduced colon carcinogenesis in rats. Cancer Lett 1994; 83: 177-184.

27. Reddy BS, Simi B, Patel N, Aliaga C, Rao CV. Effect of amount and types of dietary fat on intestinal bacterial 7 alpha-dehydroxylase and phosphatidylinositol-specific phospholipase $\mathrm{C}$ and colonic mucosal diacylglycerol kinase and PKC activities during stages of colon tumor promotion. Cancer Res 1996; 56: 2314-2320.

28. Collett ED, Davidson LA, Fan YY, Lupton JR, Chapkin RS. n-6 and n-3 polyunsaturated fatty acids differentially modulate oncogenic Ras activation in colonocytes. Am J Physiol
Cell Physiol 2001; 280: C1066-C1075.

29. Sauer LA, Blask DE, Dauchy RT. Dietary factors and growth and metabolism in experimental tumors. J Nutr Biochem 2007; 18: 637-649.

30. Novak TE, Babcock TA, Jho DH, Helton WS, Espat NJ. NF-kappa B inhibition by omega-3 fatty acids modulates LPS-stimulated macrophage TNF-alpha transcription. Am J Physiol Lung Cell Mol Physiol 2003; 284: L84-L89.

31. Stoll BA. N-3 fatty acids and lipid peroxidation in breast cancer inhibition. Br J Nutr 2002; 87: 193-198.

32. Kobayashi N, Barnard RJ, Henning SM, Elashoff D, Reddy ST, Cohen P, et al. Effect of altering dietary omega-6/ omega-3 fatty acid ratios on prostate cancer membrane composition, cyclooxygenase-2, and prostaglandin E2. Clin Cancer Res 2006; 12: 4662-4670.

33. Simopoulos AP. The importance of the ratio of omega-6/ omega-3 essential fatty acids. Biomed Pharmacother 2002; 56: 365-379.

34. Simopoulos AP, Leaf A, Salem N Jr. Workshop on the Essentiality of and Recommended Dietary Intakes for Omega-6 and Omega-3 Fatty Acids. J Am Coll Nutr 1999; 18: 487489.

35. Wallis JG, Watts JL, Browse J. Polyunsaturated fatty acid synthesis: what will they think of next? Trends Biochem Sci 2002; 27: 467-473.

36. Kang JX, Wang J, Wu L, Kang ZB. Transgenic mice: fat-1 mice convert n-6 to n-3 fatty acids. Nature 2004; 427: 504.

37. Lai L, Kang JX, Li R, Wang J, Witt WT, Yong HY, et al. Generation of cloned transgenic pigs rich in omega-3 fatty acids. Nat Biotechnol 2006; 24: 435-436. 